"Design of Crystal Structure Specific Surfactants Based on Molecular Recognition at Mineral Surfaces," Pradip, Tata Research Development \& Design Centre, Pune.

"Optical Composites," S.R. Rajagopalan, National Aeronautical Laboratory, Bangalore.

"Smart Composites," N. Balasubramanian, Eternit Everest Ltd., Bangalore.

"Al-Matrix Composites," Y.R. Mahajan, Defence Metallurgical Research Laboratory, Hyderabad.

"Sensing: Materials and Mechanisms," K.T. Jacob, Indian Institute of Science, Bangalore.

"Studies on Fuel-Clad Chemical Interactions in the FBTR," S.P. Garg, Bhabha Atomic Research Centre, Bombay.

\section{MRS-I Symposium Lectures}

\section{Symposium A-Rapid Solidification}

Processing

"Science of Rapid Solidification," P. Ramachandra Rao, Banaras Hindu University, Varanasi.

"Rapid Solidification Processing of Titanium Base Alloys," R.G. Rowe, General Electric Corporate R\&D, U.S.A.

"Rapid Solidification of Zirconium Base Alloys," G.K. Dey, Bhabha Atomic Research Centre, Bombay.

"Spray Forming--Science and Technology," S.N. Ojha, Banaras Hindu University, Varanasi.

"Nanometric Composites Through $\mathrm{RSP}_{\prime}^{\prime \prime} \mathrm{K}$. Chattopadhyay, Indian Institute of Science, Bangalore.

\section{Symposium B-Advanced Composites}

"Fiber-Reinforced Ceramic Matrix Composites," L.M. Manocha, Sardar Patel University, Vallabh Vidyanagar.

"Investigations on Hygrothermal Effects on Polymer Composites," P.K. Sinha, Indian Institute of Technology, Kharagpur.

"Aluminum Alloy Matrix Composites," B.C. Pai, R.M. Pillai, and K.G. Satyanarayana, Regional Research Laboratory, Thiruvananthapuram.

\section{Symposium C-Structural Ceramics}

"Plasma Spraying of Ceramic Powders by Sol-Gel Processing," D. Ganguly, Central Glass and Ceramic Research Institute, Calcutta, and S.V. Joshi, Defence Metallurgical Research Laboratory, Hyderabad.

"Ceramic and Metal Matrix Composites by Melt Oxidation and Infiltration," Vikram Jayaram, Indian Institute of Science, Bangalore.

"Zirconia-Toughened Ceramics," D.C. Agrawal, Indian Institute of Technology, Kanpur.

\title{
E-MRS, MatTech, f.e.m.s. Join Forces for 1992 E-MRS Fall Meeting
}

The European Materials Research Society's 1992 Fall Meeting, November 3 - 6 in Strasbourg, will feature the joint efforts of E-MRS, the MatTech East-West Conference organization, and the Federation of European Materials Societies (f.e.m.s.) in showcasing interdisciplinary materials R\&D in the 3rd European East-West Conference on Materials and Processes.

The first European East-West Symposium on Materials and Processes, MatTech' 90 held in Finland, was organized by the Institute of Materials Science and Technology of the Helsinki University of Technology. The Fransevitch Institute for Problems of Materials Science (Kiev, Ukraine) participated actively, as did 200 Soviet researchers. The second MatTech held in Finland in 1991 also featured strong participation by the USSR and Eastern European scientists. The third MatTech, being held as a joint venture with the 1992 E-MRS Fall Meeting, seeks to continue dialogue and technology transfer between Eastern and Western scientists.

Five symposia are planned, as is a special Exhibition and Contact Forum for EastWest Technology Transfer featuring achievements of Eastern countries in advanced materials.

\section{Abstract Deadline is August 1, 1992}

Abstracts from Western and Central countries should be submitted to the chairs identified in the following descriptions.

Abstracts from Eastern countries should be submitted to:

MatTech Centre East

c/o Frantsevich Institute for Problems of Materials Science

3 Krzhizhanovsky str.

$252142 \mathrm{Kiev}$, Ukraine

Phone (7) 44-444 2271 (V. Trefilov, chair)

(7) 44-444 2264 (V. Skorokhod, vice-chair)

(7) 44-444 1458 (A. Tchetchel, coordinating chief)

(7) 44-4440030 (S. Pan, scientific secretary) Fax (7) 44-444 0492 or (7) 44-444 2078

Telex 131257 stan su

\section{Symposium A-High Tc Superconductors}

This 31/2-day symposium will deal with thin films, single crystals, polycrystalline and textured materials (tapes, wires, thick films). Special attention will be paid to the influence of defects on the superconducting, other physical properties, and device performances. Emphasis will be placed on the following topics: defects in thin films and single crystals; grain boundaries and superconducting properties; influence of intrinsic and induced defects on the properties; influence of perfection of materials and multilayers on device performances; and applications.

Chairs: J. Dumas (Grenoble, France), H.W. Neumüller (Erlangen, Germany), and P.V. Seminozhenko (Kharkov, Ukraine).

Abstracts go to: J. Dumas, L.E.P.S.-CNRS, 25 , avenue des Martyrs, BP 166, 38042 Grenoble Cedex 9, France; phone (33) 768879 01; fax (33) 76887988.

Submit abstracts from Eastern countries to MatTech Centre East.

\section{Symposium B-Materials Under Extreme Conditions}

This 3-day symposium will emphasize three main subject areas: (1) materials at very high temperatures (plasticity and strength, mechanical and chemical stability, transport properties, surface protection, processing aspects, etc...); (2) materials at low temperatures (all aspects of mechanical, optical, and electronic properties of materials at cryogenic temperatures); and (3) materials at high deformation rates (rapid deformation in materials processing and applications) Original contributions from other areas will also be considered. Invited speakers will be selected from the submissions.

Chairs: G. Kostorz (Zürich, Switzerland) and V. Trefilov (Kiev, Ukraine).

Abstracts go to: G. Kostorz, Angewandte Physik, ETH Zürich, 8093 Zürich, Switzerland; phone (41) 137 73399; fax (41) 137 20540; telex: 823474 ehpz ch.

Submit abstracts from Eastern countries to MatTech Centre East.

\section{Symposium C-Nanophase Materials}

Nanostructured metals, semiconductors and ceramics have promising electronic, magnetic, and mechanical properties because of the effects of particle size and the high degree of disorder in the interfacial regions. The relationship between microstructure and properties has not been fully understood yet. The application of such materials will be in the field of net shape forming of brittle materials, sensors, electromagnetics shielding, magnetic materials, tribology, etc.... A series of invited lectures will report on the state of the art in the various aspects of this area of materials 
science. Shorter oral presentations and posters are invited.

Chairs: H-D. Kunze (Bremen, Germany), V. Troitsky (Chernogolovka, Russia), and R.Z. Valiev (Ufa, Russia).

Abstracts go to: H-D. Kunze, Frauenhofer IFAM, Lesumer Heerstr. 36, 2820 Bremen 77, Germany; phone (49) 4216383 100; fax (49) 4216383190 .

Submit abstracts from Eastern countries to MatTech Centre East.

\section{Symposium D-Biomaterials}

This two-day symposium will cover the following topics: biomaterials, electronics, computing and related problems; applications in orthopedics central and maxillofacial surgery; bioresorbable materials for hard tissue repair; drug delivery systems; artificial blood and body fluids; and blood biomaterials interactions.

Chairs: F. Burny (Brussels, Belgium), H.A. Jansons (Riga, Latvia), D. Muster (Strasbourg, France), and S. Volson (Moscow, Russia).

Abstracts go to: F. Burny, Hopital Erasme, Dept. Orthop. Trauma., Route de Lennik 808 , 1070 Brussels, Belgium; phone (32) 2

\section{Announcing a new forum for the interaction of science and technology in Advanced Materials}

\section{$\triangle D D V A N G E D D$}

MA

\section{for OPULCS and}

\section{ELECTRONICS}

Combining Chemtronics and the Journal of Molecular Electronics

\section{AIMS AND SCOPE}

Advanced Materials for Optics and Electronics aims to provide a forum for the exchange of knowledge of those materials - inorganic, organic, polymeric and biological whose focus of interest is the emerging discipline of Information Technology in its broadest sense. Its purpose is to bring about the integration and interaction of the science and technology of advanced materials whose scope includes:

Materials

Processing

Applications and Devices

For your free sample copy and further information, complete and return coupon to: Sue Stewart, John Wiley \& Sons Ltd, Baffins Lane, Chichester, West Sussex, P019 IUD, UK

\section{EDITOR-IN-CHIEF}

PROFESSOR D.J. COLEHAMILTON

University of St. Andrews, Fife, Scotland

\section{ASSOCIATE EDITORS}

DR A.R. BARRON

Harvard University, USA

PROFESSOR DR H. BASSLER

Philipps Universität Marburg,

Germany

\section{PROFESSOR J.B. MULLIN}

Worcs, UK

PROFESSOR R.W. MUNN

University of Manchester, Institute of Science \& Technology, UK

First Issue February 1992

Volume 1 (1992) Bimontbly

ISSN: 1057-9257

Institutional Subscription US $\$ 395$

Personal Subscription US $\$ 295$

Price includes postage/air speeded delivery

Please send me further information on Advanced Materials for Optics and Electronics

NAME:

POSITION

ADDRESS:

SIGNATURE DATE

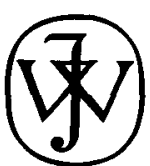

WILEY
55536 44; fax (32) 25203556.

Submit abstracts from Eastern countries to MatTech Centre East.

\section{Symposium E-Recycling of Materials in Industry}

Saving resources and energy plus environmental protection obligations motivate the strong appeal for increasing the recycling rate of materials in industry. This strategic interest is reinforced by pure economic considerations (recycling of base, strategic, and precious metals) and also new social and political constraints. Recycling is already a well-established industry with conventional materials like metals and alloys but emerging complex materials like the numerous types of thermosettings, advanced thermoplastics, fiber-reinforced materials, and metal matrix composites and others demand new technological recycling routes. Both sectors will profit from looking for new technological and methodological approaches to recycling the traditional and advanced materials (improvement of existing tools, new processes development, and better quality products for increasing the market penetration).

Chairs: M. Donato (CEE Brussels, Belgium) and S.F. Bezverrchii (Dmitrov, Russia).

Abstracts go to: $M$. Donato, CEE-DG XII, 200 Rue de la Loi, 1049 Brussels, Belgium; phone (32) 2 235 3955; fax (32) 22358046.

Submit abstracts from Eastern countries to MatTech Centre East.

Information is also available from:

P. Siffert, E-MRS - MatTech - f.e.m.s. Joint Conference, B.P. 20, 67037 Strasbourg Cedex 2, France; phone (33) 88286543 ; fax (33) 88280990 or (33) 88286293.

Kaj R. Lilius, Chair, MatTech Coordination Centre East-West, Helsinki University of Technology, Institute of Materials Science and Technology, 02150 Espoo, Finland; phone (358) 04512782 or 2198; fax (358) 04552250 or 4512799 or 4512660 .

G. Kostorz, President, f.e.m.s. Secretariat, 11 Hobart Place, London SW1W 0HL, United Kingdom; phone (44) 71245 9555; fax (44) 718231379 .

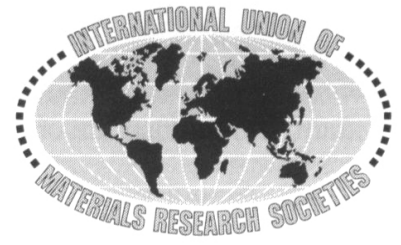

